\title{
Sex ratio and time to pregnancy: analysis of four large European population surveys
}

\section{Mike Joffe, emeritus reader, ${ }^{1}$ James Bennett, research associate, ${ }^{1}$ Nicky Best, professor of statistics and epidemiology, ${ }^{1}$ Tina Kold Jensen, professor of environmental epidemiology ${ }^{2}$}

\begin{abstract}
${ }^{1}$ Department of Epidemiology and Public Health, Imperial College, London W2 1PG

2University of Southern Denmark, Institute of Public Health, Denmark

Correspondence to: $\mathrm{M}$ Joffe m.joffe@imperial.ac.uk

doi: 10.1136/bmj.39097.508426.BE
\end{abstract}

\section{ABSTRACT}

Objective To test whether the secondary sex ratio (proportion of male births) is associated with time to pregnancy, a marker of fertility.

Setting Denmark and the United Kingdom.

Participants 49506 pregnancies.

Main outcome measure Secondary sex ratio.

James has suggested that a low secondary sex ratio could be used as an indicator of risk factors to male reproductive health (as an alternative to semen quality, hormone levels or a functional measure of biological fertility such as time to pregnancy). ${ }^{5}$ Møller has suggested that an altered secondary sex ratio should be considered as part of the testicular dysgenesis syndrome, partly on the grounds of parallel trends but
Design Analysis of four large population surveys.

Results No association was found between the sex ratio and time to pregnancy and no discernible trend was found for sex ratio with time to pregnancy, either within individual datasets or in the pooled analysis. The odds ratios were 0.97 (95\% confidence interval 0.90 to 1.04 ) for contraceptive failures, 1.01 (0.96 to 1.05$)$ for time to pregnancy of 2-4 months, 1.02 (0.97 to 1.08) for 5-10 months, 0.98 (0.93 to 1.03) for 11 months or more, and 0.88 ( 0.74 to 1.06 ) for fertility treatment, with 0-1 months as the reference category. Conclusion No association was found between the secondary sex ratio and time to pregnancy.

\section{INTRODUCTION}

Evidence exists of a decline in semen quality over recent decades and a deterioration in the reproductive health of males, with an increase in the incidence of testicular cancer and probably of hypospadias and cryptorchidism-the "testicular dysgenesis syndrome". ${ }^{1}$ One cause that has been suggested is endocrine disruption due to environmental agents with oestrogenic or antiandrogenic effects, although direct evidence is lacking and other mechanisms are possible. ${ }^{1}$ Other things being equal, a decline in semen quality is expected to be followed by a declining trend in fertility, although during the same period no such decline-as measured by the time to pregnancy-has been observed. ${ }^{2}$

In parallel, during the same period the proportion of male offspring (commonly called the secondary sex ratio) has been declining in many countries, including the United States and Canada and several European countries. $^{34}$ An association between fertility and secondary sex ratio could in principle result from universal biological processes (for example, the frequency and timing of intercourse relative to ovulation or levels of sex hormones in either partner) or from exposure to a toxin that affects both end points. also because a case-control study of men with testicular cancer found an excess of female offspring (albeit of borderline significance) born two years or more before the father's diagnosis. ${ }^{4}$ This observation was confirmed in a study of Danish men born during 1945-80. ${ }^{6}$ The same association was not, however, observed at the aggregate level, in that Finland has a low incidence of testicular cancer compared with the other Nordic countries but also a low secondary sex ratio. ${ }^{4}$ Moreover, among 15218 men who attended the Sperm Analysis Laboratory in Copenhagen for various reasons (most commonly infertility), no association was found between the secondary sex ratio and any semen characteristics. ${ }^{7}$ Exposure to certain substances, such as the nematocide dibromochlorpropane ${ }^{8}$ and $\operatorname{dioxin}^{9}$ and related substances, ${ }^{1011}$ has been found to affect the secondary sex ratio and male fertility in a parallel way.

This parallelism of trend taken together with shared chemical determinants raises the question of whether the probability of conceiving a male child is linked to the parents' fertility. Such an association would suggest that these chemical agents, or others with a similar mode of action, may be causing the observed parallel trends in the secondary sex ratio and male fertility. In other words, the association would link the secondary sex ratio with the testicular dysgenesis syndrome and could lead towards elucidating the underlying cause of the secondary sex ratio and fertility, whether hormonal or not.

We tested the hypothesis that the secondary sex ratio is associated with the time to pregnancy, a marker of fertility, ${ }^{12}$ using four high quality datasets from previous population surveys.

\section{METHODS}

We used datasets from four major European studies with population based samples: the Odense prenatal 
study (Denmark), ${ }^{13}$ the Asclepios project (an occupational study), ${ }^{14}$ the Office for National Statistics omnibus study (representative of Great Britain), ${ }^{2}$ and the Millennium cohort study (representative of the United Kingdom). ${ }^{15}$

We identified 49506 liveborn singletons conceived without fertility treatment. Information on conception was obtained by questionnaire, which has been shown to be a valid, even after 20 years of recall. ${ }^{16} \mathrm{We}$ classified pregnancies into contraceptive failures and those with a time to pregnancy of $0-1$ months (reference category), 2-4 months, 5-10 months, and 11 months or more. Data on a further 496 babies born after fertility treatment were available and we included these as an additional category in the pooled analysis across all datasets (numbers were too small for inclusion of this category in the study specific analyses). Data on contraceptive failures were not reliably available from the Millennium cohort questionnaire.

We used logistic regression to examine the association between pregnancy categories and secondary sex ratio, adjusting for birth order, age of both parents (grouped), and study. To account for the lack of independence of observations due to about $40 \%$ of couples in the Odense dataset having more than one child we included a random effect for each couple in the model. To implement this we used penalised quasilikelihood ${ }^{17}$ through the command glmmPQL in the software SPLUS.

\section{RESULTS}

Table 1 lists the details of the four major European surveys providing datasets. The figure shows the distribution of pregnancy categories for each study. Some differences between studies are apparent, which may reflect variations in couple fertility in time or space.

No association between secondary sex ratio and degree of fertility was observed for any of the studies separately or when pooled (table 2). For the pooled analysis the odds ratios were 0.97 (95\% confidence interval 0.90 to 1.04 ) for contraceptive failures and 1.01 (0.96 to 1.05$)$ for time to pregnancy of 2-4 months, 1.02 (0.97 to 1.08$)$ for 5-10 months, and 0.98 (0.93 to 1.03 ) for 11 months or more, with 0-1 months as the reference category. The odds of having a male offspring after successful fertility treatment were reduced $(0.88,0.74$ to 1.06$)$. Although the odds ratios show small departures from 1.0, the confidence intervals all include 1.0 and no trends can be seen for the individual studies or for the pooled analysis. The influence of clustering within couples was negligible, with almost identical results being produced for the analyses including random effects (table 2) and excluding random effects (results not shown).

An analysis using a dichotomous split of time to pregnancy corresponding to "clinical infertility" produced an odds ratio of 0.97 (95\% confidence interval 0.93 to 1.03 ) for those with a time to pregnancy of 12 months or more compared with those classified as contraceptive failures or with a time to pregnancy of less than 12 months. A further analysis was carried out using time to pregnancy as a continuous variable, excluding contraceptive failures, fertility treated couples, and those with a time to pregnancy of more than 36 months, leaving 44209 babies. The exclusions prevented the small number of extreme values for time to pregnancy from influencing the fitted regression line. This produced a statistically non-significant regression coefficient $(-0.0014,95 \%$ confidence interval -0.0042 to 0.0013$)$.

\section{DISCUSSION}

Using datasets from four large European studies we found no association between time to pregnancy (a marker of fertility) and secondary sex ratio (proportion of male births). No patterns were apparent to suggest a significant result if larger population numbers had been available.

Assuming no misclassification of time to pregnancy, we determined that the main analysis (excluding babies conceived after fertility treatment) had 99\% power to detect a $4 \%$ difference in the percentage of male births between the top category (contraceptive failures) and bottom category (time to pregnancy 11 months or more). It also had a power of $93 \%$ to detect a difference of $3 \%$ between the categories, but a power of only $57 \%$ to detect a difference of $2 \%$. Although differences of $2 \%-4 \%$ in the secondary sex ratio represent large effects, these were none the less smaller than the $6.5 \%$ difference in proportion of male births found by one study, ${ }^{18}$ which compared couples with times to pregnancy of less than 12 months with those waiting at least 12 months.

\begin{tabular}{|c|c|c|c|c|c|}
\hline Study (location) & Study design & $\begin{array}{l}\text { Timing of data } \\
\text { collection }\end{array}$ & Study period & $\begin{array}{c}\text { Response } \\
\text { rate (\%) }\end{array}$ & $\begin{array}{l}\text { Respondents who had } \\
\text { become parents (\%)* }\end{array}$ \\
\hline $\begin{array}{l}\text { Odense prenatal study (Fyn, } \\
\text { Denmark) }\end{array}$ & Pregnancy based & $\begin{array}{l}\text { In antenatal clinic at } \\
\text { around } 20 \text { weeks' } \\
\text { gestation }\end{array}$ & $1972-97$ & 92 & 100 \\
\hline $\begin{array}{l}\text { Asclepios project (European Union } \\
\text { occupational study) }\end{array}$ & Cross sectional & $\begin{array}{l}\text { Lifetime reproductive } \\
\text { history; youngest child }\end{array}$ & $1995-8$ & 57 & 86 \\
\hline $\begin{array}{l}\text { Office for National Statistics } \\
\text { omnibus study (Great Britain) }\end{array}$ & Cross sectional & $\begin{array}{l}\text { Lifetime reproductive } \\
\text { history; first pregnancy }\end{array}$ & 1996 & 72 & 73 \\
\hline $\begin{array}{l}\text { Millennium cohort study (United } \\
\text { Kingdom) }\end{array}$ & Pregnancy based & $\begin{array}{l}\text { When child was aged } \\
\text { about } 9 \text { months }\end{array}$ & $2001-2$ & 82 & 52 \\
\hline
\end{tabular}


Table 2 | Male births in relation to contraceptive failures and time to pregnancy. Values are odds ratios (95\% confidence intervals) unless stated otherwise

\begin{tabular}{|c|c|c|c|c|c|c|c|}
\hline \multirow[t]{2}{*}{ Study } & \multirow{2}{*}{$\begin{array}{l}\text { No of } \\
\text { births }\end{array}$} & \multirow{2}{*}{$\begin{array}{l}\text { Contraceptive } \\
\text { failures }\end{array}$} & \multicolumn{4}{|c|}{ Time to pregnancy (months)* } & \multirow{2}{*}{$\begin{array}{c}\text { No of births } \\
\text { after } \\
\text { fertility } \\
\text { treatment }\end{array}$} \\
\hline & & & $\begin{array}{l}0-1 \\
\text { (refer- } \\
\text { ence } \\
\text { group) }\end{array}$ & $2-4$ & $5-10$ & $\geq 11$ & \\
\hline Odense prenatal study & 36674 & 0.98 (0.91 to 1.06$)$ & 1.0 & $1.00(0.95$ to 1.06$)$ & $1.00(0.94$ to 1.07$)$ & $0.97(0.91$ to 1.04$)$ & NA \\
\hline Asclepios project & 1797 & $0.75(0.52$ to 1.08$)$ & 1.0 & $0.93(0.74$ to 1.16$)$ & $1.12(0.82$ to 1.52$)$ & $1.03(0.73$ to 1.45$)$ & 45 \\
\hline $\begin{array}{l}\text { Office for National } \\
\text { Statistics omnibus study }\end{array}$ & 1817 & $0.92(0.69$ to 1.24$)$ & 1.0 & $0.99(0.77$ to 1.27$)$ & $1.18(0.85$ to 1.63$)$ & $1.10(0.82$ to 1.48$)$ & 60 \\
\hline Millennium cohort study & 9218 & NA & 1.0 & $1.05(0.95$ to 1.16$)$ & $1.08(0.95$ to 1.22$)$ & $0.97(0.86$ to 1.11$)$ & 391 \\
\hline Pooled & 49506 & 0.97 (0.90 to 1.04$)$ & 1.0 & 1.01 (0.96 to 1.05$)$ & $1.02(0.97$ to 1.08$)$ & $0.98(0.93$ to 1.03$)$ & $\begin{array}{c}0.88(0.74 \text { to } \\
1.06) \dagger \\
\end{array}$ \\
\hline
\end{tabular}

Even allowing for non-differential misclassification of time to pregnancy ${ }^{16}$ our study was of sufficient power to detect a difference in the proportion of male births similar to that found previously. ${ }^{18}$ If we assume a true underlying difference of $6.5 \%$ in the secondary sex ratio between couples with times to pregnancy of 12 months or less and a sensitivity of $79.9 \%$ and specificity of $94.9 \%$ for the binary indicator of time to pregnancy ${ }^{16}$ then following the working in Armstrong et al ${ }^{19}$ we would still expect to observe a difference of over $4 \%$ in the proportion of male births between the two groups after allowing for misclassification.

Although several biases may occur in studies of times to pregnancy if they are not designed and analysed well, ${ }^{12}$ these primarily affect the design, analysis, and interpretation of studies using time to pregnancy as the outcome rather than as a predictor, as in our study. Furthermore, these biases are unlikely to be affected by the sex of the baby. We therefore believe that this is a truly negative study.

Few studies have been published on the possible association between fertility and the probability of a male offspring. One study found that in a population exposed to pesticides males tended to be conceived more quickly than females. ${ }^{20}$ Another study found a

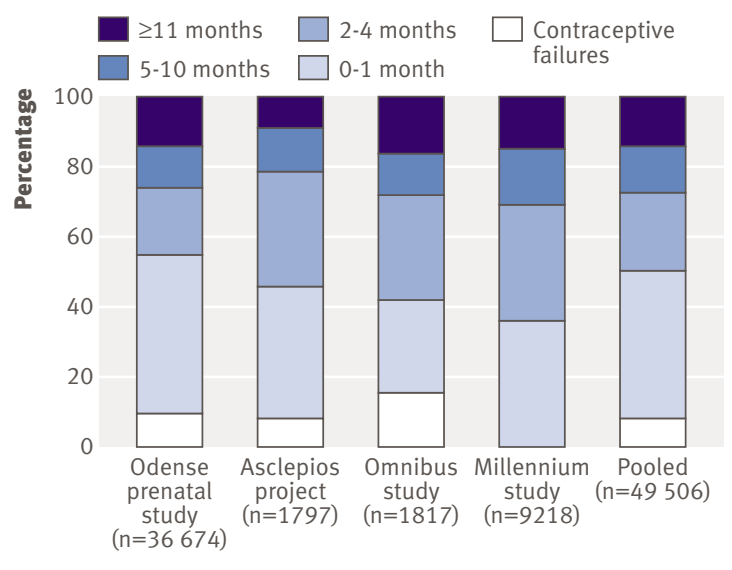

Distribution of times to pregnancy by dataset deficit of males among pregnancies that took more than a year to achieve. ${ }^{21}$ On the other hand, Smits et al found an increasing proportion of males born with longer waiting times to pregnancy. ${ }^{18}$ These contradictory findings are based on relatively small studies, and so the lack of an association we found using a larger dataset is not incompatible with this earlier literature; there could also be other negative studies that have not been published. Indeed, two large unpublished analyses have been posted on the BMJ website, ${ }^{2223}$ both of which found no association. Together with our study the sample size is almost 130000 . Although time to pregnancy is affected only by severely abnormal semen quality, this combined sample should have been sufficient to detect an association if one were present, even if it was smaller than that found by Smits et al. ${ }^{18}$ Nevertheless, the associations seen in the published studies could be real ${ }^{182021}$ : they could have resulted if the populations that they were based on had been exposed to an environmental agent that affected both the secondary sex ratio and time to pregnancy.

We were motivated to test our hypothesis because of parallel historical trends in the secondary sex ratio and health of the male reproductive system, as manifest by the testicular dysgenesis syndrome, which could indicate that whatever exposure is responsible for an increasing trend in this syndrome is also causing a reduction in the secondary sex ratio. This is supported by evidence from studies of exposed populations. Paternal occupational exposure to the nematocide dibromochlorpropane has been found to greatly impair male fertility, in some cases causing permanent sterility; the probability of a male birth was greatly reduced among those men who retained or recovered their fertility. ${ }^{8}$

In rodents even a low dose of dioxin impaired spermatogenesis. ${ }^{9}$ This outcome has been judged the critical end point of dioxin in that effects occur at a lower dose than for any other outcome. Certain polychlorinated biphenyls have dioxin-like effects, ${ }^{9}$ and more generally these and other agents that disrupt the 


\section{WHAT IS ALREADY KNOWN ON THIS TOPIC}

Semen quality and the probability of a male birth have both declined in recent decades

The two may be linked, as certain chemical agents affect both of them

\section{WHAT THIS STUDY ADDS}

No association was found between time to pregnancy and the secondary sex ratio (proportion of male offspring) the interpretation of the findings. MJ drafted the manuscript, and all authors contributed to the final draft. MJ is the guarantor.

Funding: Medical Research Council (strategic project grant No G9900635).

Competing interests: None declared.

Ethical approval: Not required.

1 Joffe M. Infertility and environmental pollutants. Brit Med Bull 2003;68:47-70.

2 Joffe M. Time trends in biological fertility in Britain. Lancet 2000;355:1961-5.

3 Davis DL, Gottlieb MB, Stampnitzky JR. Reduced ratio of male to female births in several industrial countries: a sentinel health indicator? JAMA 1998;279:1018-23.

endocrine system may possibly cause impairment of the male reproductive system. ${ }^{11011}$ In humans, paternal exposure has been observed to affect the secondary sex ratio in some studies but not in others. ${ }^{1011}$

This perspective offers a reconciliation of our findings, those posted on the $B M J$ website, and those of Smits et al. Our study population covered several European countries, and the observed lack of association between time to pregnancy and the secondary sex ratio suggests that there is no relevant exposure common to all these countries. On the other hand, the population in Smits et al's study was drawn from a region in the Netherlands, which could be exposed to an environmental agent that has not so far been recognised. If so it would be a valuable clue in an area of research where such clues are urgently needed.

Alternatively, the secondary sex ratio and fertility could be linked through the female reproductive system, but the science here is unclear. Intercourse close to ovulation has been suggested to result in more males. $^{24}$ As this would also lead to a relatively high probability of conception, male births would be associated with a shorter time before conception. Others, however, have suggested the opposite, on the basis of a different biological mechanism. ${ }^{25}$ We could find no evidence to support either of these hypotheses.

\section{CONCLUSION}

Our findings of no evidence of an association between the secondary sex ratio and time to pregnancy concur with those of other large studies reported on the BMJ website. The pregnancies that we studied occurred during the past few decades in western Europe, where semen quality is thought to have declined ${ }^{1}$ in parallel with a decrease in proportion of male births. ${ }^{34}$ If these two phenomena were due to the same environmental agent (for example, dioxin or another agent that disrupts the endocrine system), we would expect to have found an association between relatively long times to pregnancy and a decrease in the secondary sex ratio. The lack of an association between the two in our study provides no evidence of a shared environmental cause. Neither do our findings offer any support for alternative hypotheses linking fertility and the secondary sex ratio through the female reproductive system.

We thank Maria He Huang-Wong and Jane Key who organised the datasets and carried out quality control, and those who created the datasets used in this study.

Contributors: MJ conceived the study. MJ, NB, and TKJ developed the proposal to test the hypothesis. JB analysed the data. All authors contributed to
4 Møller $\mathrm{H}$. Trends in sex ratio, testicular cancer and male reproductive hazards: are they connected? APMIS 1998;106:232-9.

5 James WH. Male reproductive hazards and occupation. Lancet 1996;347:773.

6 Jacobsen R, Bostofte E, Engholm G, Hansen J, Skakkebaek NE, Mølle $H$. Fertility and offspring sex ratio of men who develop testicular cancer: a record linkage study. Hum Reprod 2000;15:1958-61.

7 Jacobsen R, Bostofte E, Skakkebaek NE, Hansen J, Møller H. Offspring sex ratio of subfertile men and men with abnormal sperm characteristics. Hum Reprod 2000;15:2369-70.

8 Potashnik G, Porath A. Dibromochlorpropane (DBCP): a 17-year reassessment of testicular function and reproductive performance. J Occup Environ Med 1995;37:1287-92.

9 Committee on Toxicity of Chemicals in Food, Consumer Products and the Environment. Statement on the tolerable daily intake for dioxins and dioxin-like polychlorinated biphenyls. London: Food Standards Agency, 2001. www.food.gov.uk/science/ouradvisors/toxicity/ statements/cotstatements2001/dioxinsstate (accessed 2 Oct 2006).

10 Richthoff J, Rylander L, Jonsson BA, Akesson H, Hafmar L, Nilsson-Ehle $P$, et al. Serum levels of $2,2^{\prime}, 4,4^{\prime}, 5,5^{\prime}$ hexachlorobiphenyl (CB-153) in relation to markers of reproductive function in young males from the general Swedish population.

11 Karmaus W, Huang S, Cameron L. Parental concentration of Michigan fish eaters and sex ratio in offspring. J Occup Environ Med 2002;44:8-13.

12 Joffe M, Key J, Best N, Keiding N, Scheike T, Jensen TK. Studying time to pregnancy using a retrospective design. Am J Epidemiol 2005;162:115-24.

13 Jensen TK, Scheike T, Keiding N, Schaumburg I, et al. Selection bias in determining the age dependence of waiting time to pregnancy. $\mathrm{Am}$ Epidemiol 2000;152:565-72.

14 Joffe M, Bisanti L, Apostoli P, Kiss P, Dale A, Roeleveld N, et al. Time to pregnancy and occupational lead exposure. Occup Env Med 2003;60:752-8.

15 Millennium Cohort Study. www.cls.ioe.ac.uk/studies.asp? section $=000100020001$ (accessed 2 Oct 2006).

16 Joffe M, Villard L, Li Z, Plowman R, Vessey M. A time to pregnancy questionnaire designed for long term recall: validity in Oxford, England. J Epidemiol Community Health 1995;49:314-9.

17 Breslow NE, Clayton DG. Approximate inference in generalized linear mixed models. J Am Stat Assoc 1993;88:9-25.

18 Smits LJM, de Bie RA, Essed GG, van den Brandt PA. Time to pregnancy and sex of offspring: cohort study. BMJ 2005;331:1437-8.

19 Armstrong BK, White E, Saracci R. Principles of exposure measurement in epidemiology. Oxford: Oxford University Press, 1995.

20 De Cock J, Heederik D, Tielemans E, te Veld E, van Kooij R. Offspring sex ratio as an indicator of reproductive hazards associated with pesticides [author's reply]. Occup Environ Med 1995;52:429-30.

21 Weijin Z, Olsen J. Offspring sex ratio as an indicator of reproductive hazards. Occup Environ Med 1996;53:503-4.

22 Olsen J, Weijin Z, Jin LZ. Time to pregnancy and sex of offspring. BM rapid responses http://bmj.bmjjournals.com/cgi/eletters/331/ 7530/1437\#124413 (accessed 2 Oct 2006).

23 Slama R, Bouyer J, Ducot B, Spira A, Blondel B. Are subfertile couples more likely to have boys? A comprehensive nationwide study. BMJ rapid responses http://bmj.bmjjournals.com/cgi/eletters/331/ 7530/1437\#125410 (accessed 2 Oct 2006).

24 France JT, Graham FM, Gosling L, Hair P, Knox BS. Characteristics of natural conceptual cycles occurring in a prospective study of sex preselection: fertility awareness, symptoms, hormone levels, sperm survival, and pregnancy outcome. Int J Fertil 1992;37:244-55.

25 Martin JF. Length of the follicular phase, time of insemination, coital rate and the sex of the offspring. Hum Reprod 1997;12:611-6.

Accepted: 22 December 2006 Environ Health Perspect 2003;111:409-13. dichlorodiphenyl dichloroethene and polychlorinated biphenyls in 